\title{
Remote-controlled Laboratories of Experimental Physics: Measuring the Stiffness of a Spring
}

\author{
AL Sabri Ahmed1, Khazri Yassine ${ }^{1}$, Moussetad Mohamed ${ }^{1}$, Akensous Youness ${ }^{2}$, Fahli Ahmed ${ }^{3}$ \\ ${ }^{1}$ LIMAT, Faculty of Sciences Ben M'sik, Hassan II University Casablanca, Morocco \\ ${ }^{2}$ GAGE, Faculty of Sciences Ben M'sik, Hassan II University Casablanca, Morocco \\ ${ }^{3}$ Faculty of Sciences and Techniques, Hassan I University Settat, Morocco \\ a.alsabri2011@gmail.com
}

\begin{abstract}
In modern E-Learning, students and scientists will be able to access Web portals for scientific computer and data infrastructures, thus accessing large collections of data and digital objects using metadata, knowledge management techniques, and specific data services. Students will apply existing scalable Web and grid technologies to access and share scientific data, using educational and computing resources to run scientific Practical exercises. Such an approach will allow the creation of enriched interactive through a real devices and real remote mechanisms that interactively support the exploration of scientific phenomena. Advanced repository and collaboration services will allow students to remotely and securely up- and download science and engineering learning objects. E-lab is essentially created to realize experiments by interacting with real devices that are real remote mechanisms, through an appropriate telecommunications platform, equipped with a dedicated management system and a number of software interfaces and material. Our works is aiming to: Measurement of the rigidity of a spring. This method translator pedagogical experiences and turn them into reality at an affordable, expand research sources to students.
\end{abstract}

Keywords-learning; data infrastructures; scientific computer; data services Practical exercises; E-lab; experiences experiences.

\section{Introduction}

Since 1990s, there have been consistent efforts in developing web-based education environment at many institutions around the world. Many educators have strong feelings about the relative merits of different technologies to be used in engineering laboratories. The argument is significant because it is clear that the choice of laboratory technologies could change the economics of engineering education, and it is also clear that changing the technology could change the effectiveness of education [1].

The Information and communication technologies (ICT) play key roles in transforming traditional laboratory into flexible and open learning spaces. It includes any communication device or application, encompassing: radio, television, cellular phones, computer and network hardware and software, satellite systems and so on, as well as the various services and applications associated with them, such as videoconferencing and distance learning. ICTs are often spoken of in a particular context in education, health care, or libraries. In this paper, we use this technology in education of practical experiences. So the 
AL Sabri Ahmed, Khazri Yassine, Moussetad Mohamed, Akensous Youness, Fahli Ahmed, Remote-controlled Laboratories of Experimental Physics: Measuring the Stiffness of a Spring. Transactions on Machine Learning and Artificial Intelligence, Vol 5 No 4 August (2017); p: 231-239

practical experience is an important component of the educational process. However, the time and economical resources often required for the setting up and construction of scientific laboratories is outside the scope of many institutions [2] [3]. The practical work of laboratories is subject to constraints for example: students with disabilities may have less of a chance than other students to interact in laboratory environments. Thus the remote laboratories make an economic problem to Moroccan universities, also an important facilitator for students who, for any reasons must take courses remotely in order to increasing number of students. Moreover, the advantages and motivations: protecting the students while conducting experiments involving health hazards (e.g., radioactivity, UV ...), eliminating time and space constraints through affording flexibility, affording the opportunity for conducting an online experiment with real equipment anytime and anywhere and reducing the cost of lab equipment which is expensive [4] [5].

\section{Technology background}

\subsection{Technology and Architecture}

Our previous research was based on the use and construction of remote laboratory now we describe the technology that has been constructed, so that we will provide a context for the discussion of the assessment model for those whom they are not familiar with remote laboratory. The Remote Laboratory Experimentation represents an extension to the ways in which people utilize the Internet. A remote laboratory for engineering education should achieve an integrated environment for the user controlling the actual device in the remote site and conduct the actual experiments in the remote laboratory via a computer network [6]. The core of the Remote Laboratory is a set of general and / or specialized instruments linked to a set of personal computer systems connected to the Internet. With the ability to remotely configure instruments and data analysis through software, the laboratory will facilitate the sharing of expensive instruments and equipments. The development of a remote laboratory includes the analysis of user requirements, remote control functionalities, simultaneous user operation, sharing the online data from an experiment, read data, change variables and controlling equipments. To achieve the above, a distributed client-server environment has been designed (the hardware architecture for the remote laboratory system is shown in Fig. 1. Using this architecture, the learners will be able to send themselves, orders through the web browser. Computers in the Remote Lab are connected to engineering instruments. When students log in to these machines over the Internet, they are able to control both the computer and the equipment. A video camera can also be used to broadcast live, what is happening in the physical world. It does not matter if the student is in a dormitory nearby or on the other side of the world [7]. 


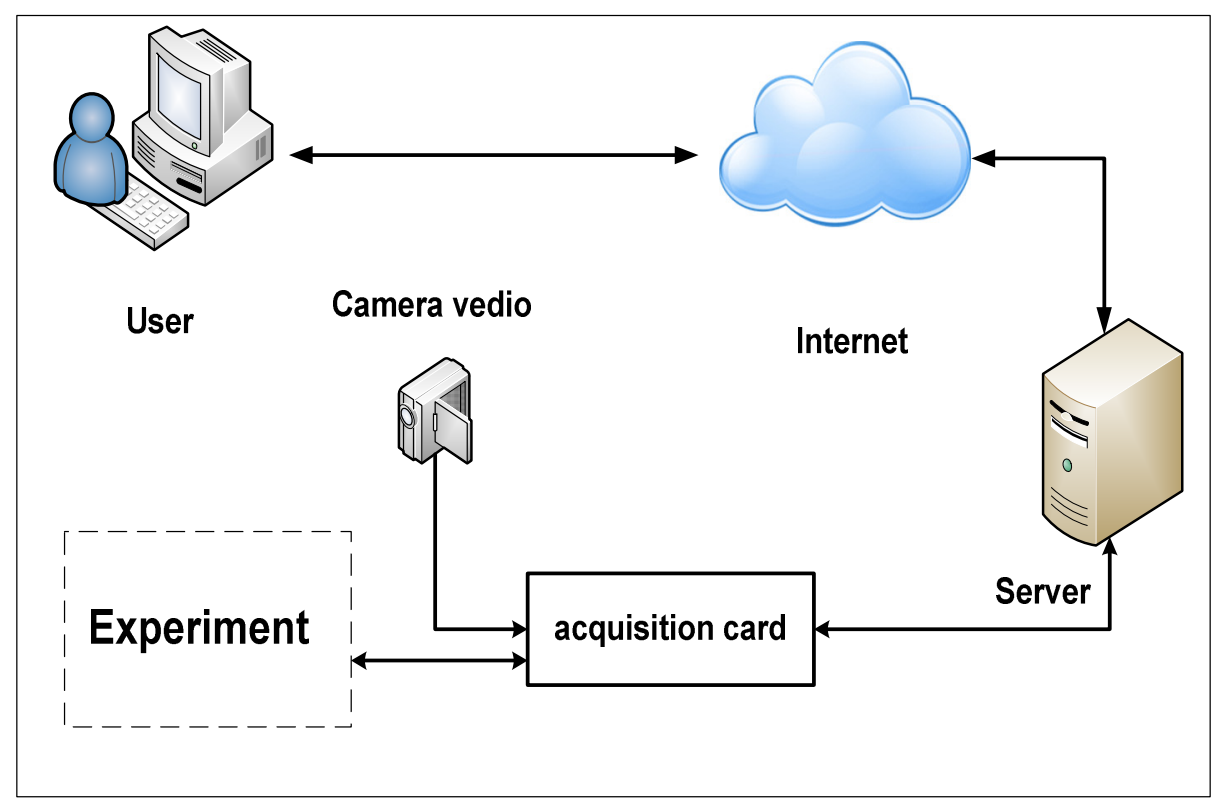

Figure 1 Architecture of Remote Laboratory

\subsection{Study Theory of Measuring The Stiffness of a Spring}

Mechanic's experience of material point represents an example for the experimental setups implemented so far on our project. An experimental setup for calculating the stiffness of a spring was designed in a modular fashion, which allows straightforward extension to multiple degrees of freedom as is shown in Fig. 3. It is proposed in this manipulation to measure experimentally the stiffness $K$ (spring constant). A spring constant is the measure of the stiffness of a spring. If a mass $m$ is attached to the lower end of the spring with empty length Lo, the spring stretches a distance $d$ from its initial position under the influence of the "load" weight shown schematically in Fig. 2.

$$
P=m g
$$

The downward force $\boldsymbol{P}$ must be balanced by the upward restoring force of the spring when the system is at rest.

$$
F=P=m g
$$

According to Hooke's law the restoring force of the spring is directly proportional to the elongation within the elastic limit (the maximum a spring can stretch without being permanently deformed) and can be written as

$$
F=-k d
$$

Where $\mathrm{F}$ is the restoring force in Newton $(\mathrm{N}), \mathrm{k}$ is the spring constant in $(\mathrm{N} / \mathrm{m})$ and $\mathrm{d}$ is the elongation (the stretched amount) in Meters (m). The restoring force is in the opposite direction to its elongation, as shown by the minus sign. When the applied force (the loaded weight) is used in the calculation, the minus sign is not used and the above equation can be written as:

$$
F=\boldsymbol{k} \boldsymbol{d} \text { or } \boldsymbol{m g}=\boldsymbol{k} \boldsymbol{d}
$$

The spring constant, $\mathrm{k}$, can therefore be calculated.

$$
K=\frac{F}{d}=\frac{m g}{d}
$$

Where

$$
d=L_{e q}-L_{0}
$$




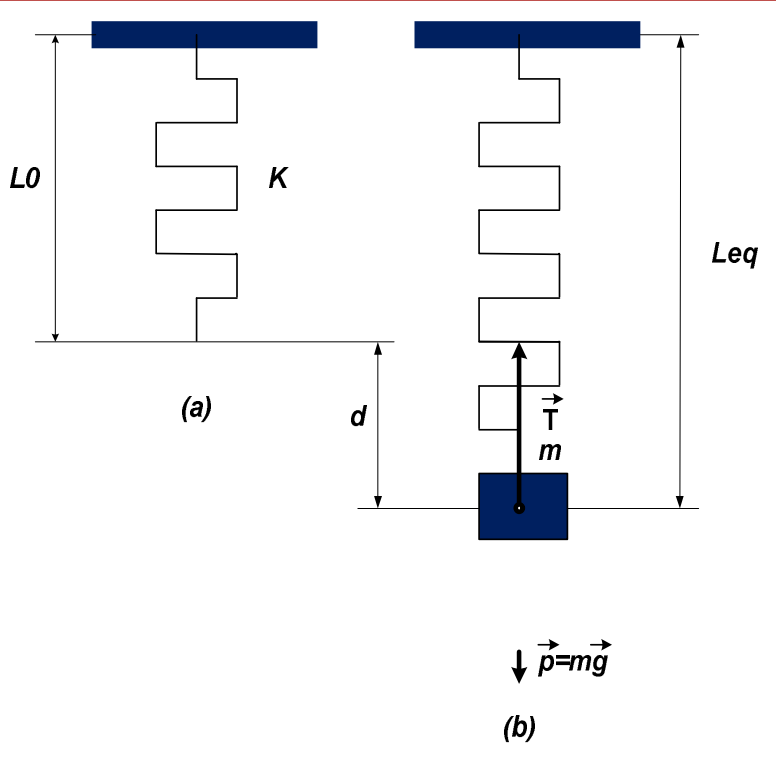

Figure 2 Mechanical system of mass-spring

(a): Spring not loaded, (b): Spring loaded in equilibrium

\subsection{Pedagogical use of the Remote Laboratories}

The remote laboratory experiments are introduced to students progressively. Here we describe the three phases that the instructor leads the student through by using a video that will be presented in our interface. In the first phase, the students are tasked with re-familiarizing themselves with the underlying physical principles, the experimental equipment and procedure of the particular experiment to be performed. A guidebook (Supporting background materials) is provided also an online documentation [8].

The second phase of the laboratory experience is directed to the laboratory facility under using a tutorial video and a tutorial guide (how to use the technology). This experimental portion is designed in such a fashion that it fits within a time period that is significantly shorter than a traditionally structured laboratory session. Thus this approach retains some - albeit brief by traditional standards - elements of a hands-on experimental experience. Furthermore, the students can watch a video from the instructor describing all steps, thus facilitating the later execution of the remote laboratory assignment. In the third stage, the students continue more detailed experimental studies in a platform of a remote lab (remote fashion way). Typically, one week is given for the student to complete the experiment and filled in the report of the experiment. The described approach leverages a limited number of experimental stations for a wide variety of studies [1] [9] .

\subsection{Usage of the Remote Laboratories}

The remote laboratory project presented in this paper is illustrated by the following example; the measurement of a spring stiffness. During First step of laboratory usage, the students can run a free test after; connection to the robot is completed. All technical issues related to the use of the robot and calibration of the system as well as data acquisition can be on the platform of the laboratory (represented in a video and documentation). In order to avoid the repetition of experimental procedures, the selection part of the type of experience, facilitates and avoids the students the repetition of inputting data. After 
describing how the students will perform the manipulation, the data in the form of measurement carry out by the platform will be elaborated to complete a form and make the necessaries calculus [1] [10].

\section{The e-Lab system}

In order to define a Remote Laboratory system, enabling real laboratory equipment (like a spring) to be remotely controlled by the student using a domestic Internet connection, we collected the following requirements:

Students should not need any special software to carry out their experience, and then it must be Webbased. As any Web page, it should accessed by means of a standard Web browser. The implementation should take on consideration web protocols and common components to guarantee the desired Web compatibility. It must manage security features

A coordinating supervisor should manage the laboratory session, to ensure security and managing of futures, authorize the control requests and to protect the equipment against any potentially damaging operation.

A standard approach must be defined to cover a large range of computer controlled lab equipments, so that the e-lab will be reusable over different lab types.

The approach should consider the main features of a collaborative Web application.

The e-lab platform scenario is that of a real classroom, which must remotely use a lab equipment located anywhere in a real laboratory. The real classroom is composed of a speaker (video made by a tutor) who will describe and comment the experience, as well as facilitating the use of the platform for the student connected to the Internet at least via a domestic ADSL. Students can remotely use the equipment and they can remotely control it [6] [7].

\subsection{The e-Lab Platform}

According to the above requirements, we will describe our e-lab platform project, which is a remote control of the robot (will be used to move mass then the Measuring the stiffness of a spring) of our Research Department. The main components of the e-Lab system are:

\subsection{Hardware and Software Tools}

To realize our system we use the next compensates:

\section{Hardware}

Acquisition card (Arduino uno)

Server

4 Servo motors

Camera video

Robotic Arm

\section{Software}

Visual basic (Microsoft Visual Studio 2010 Express).

Arduino 1.6.5 
AL Sabri Ahmed, Khazri Yassine, Moussetad Mohamed, Akensous Youness, Fahli Ahmed, Remote-controlled Laboratories of Experimental Physics: Measuring the Stiffness of a Spring. Transactions on Machine Learning and Artificial Intelligence, Vol 5 No 4 August (2017); p: 231-239

\subsection{Mechanical system}

In order to automate the mass-spring mechanism we modified the system to command our system remotely easily. Our model consists of a spring, ultrasonic sensor, mass and a reflection disk. The ultrasonic sensor is fixed at the top of the system to emit the waves towards the reflection disk (transceiver) and send the data to the acquisition card during the mass change. The Fig. 3 illustrates a mechanical system

\subsection{Acquisition Card}

The data controlling unit is an embedded system platform. For this propose, we are used an Arduino Uno. It is powered by $9 \mathrm{~V}$ from power \& programmed for the specific applications using Arduino open source software. The robot consists of 4 servo motors to be able to move smoothly into four themes, for moving the masses and hooking them to the determination of the spring. The 4 servo motors are connected to Arduino Uno, by Pin 8, Pin 9, Pin 10 and Pin 11 to send the control of each motor whereas an ultrasonic sensor is connected to Arduino Uno by Pin Analog.

This sensor collects information data and sends it to the Arduino Uno for digitally processing analysis of data. The ultrasonic sensor takes the information data from the mechanical part and send it to acquisition card[8]. The electronic diagram of Acquisition Card is shown in Fig. 4.

\subsection{The User Interface}

The e-lab user interface design and customized as a web application (shows Fig. 5). The design includes three task areas: on the left-hand side there is the video area, showing what happens in the lab room. The middle side of the screen contains the area with the Tools Panel; the Tools Panel is organized with thumbnails each displaying an experimental test, also use equipment of the lab. The left side of the application contains the field of connection to the lab equipments (robot). 


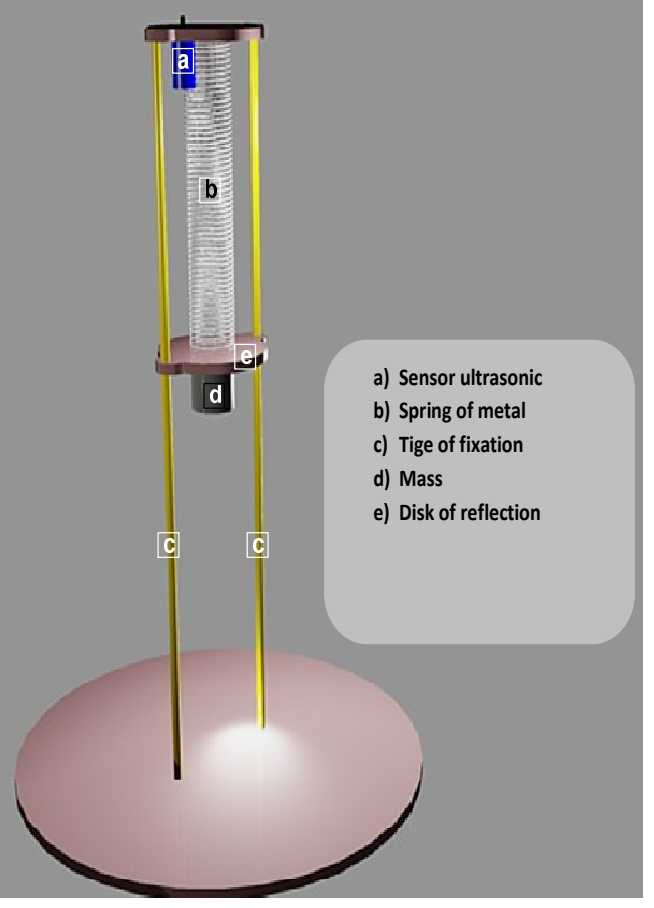

Figure 3 Design model of mechanical system

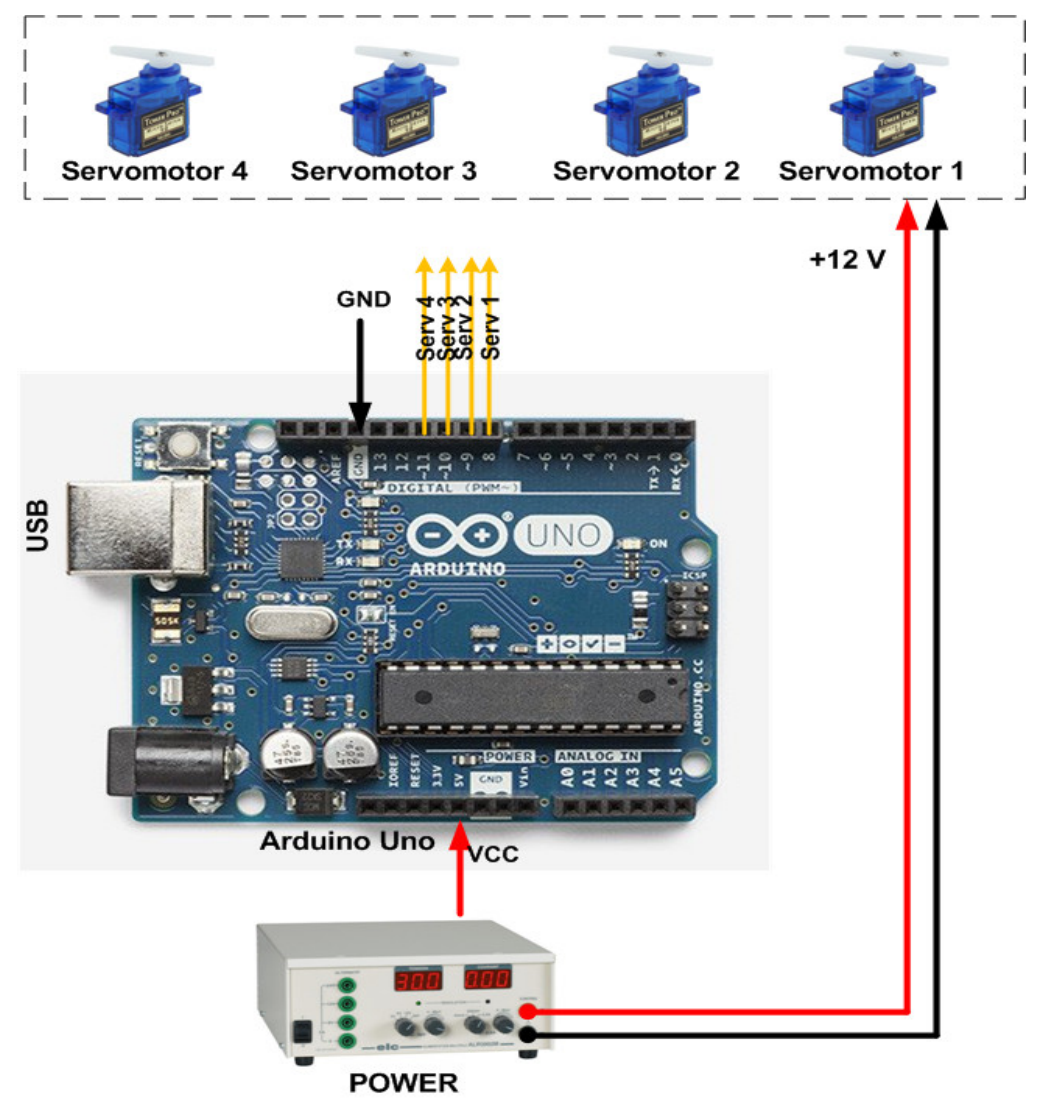

Figure 4 The electronic diagram of Acquisition Card 


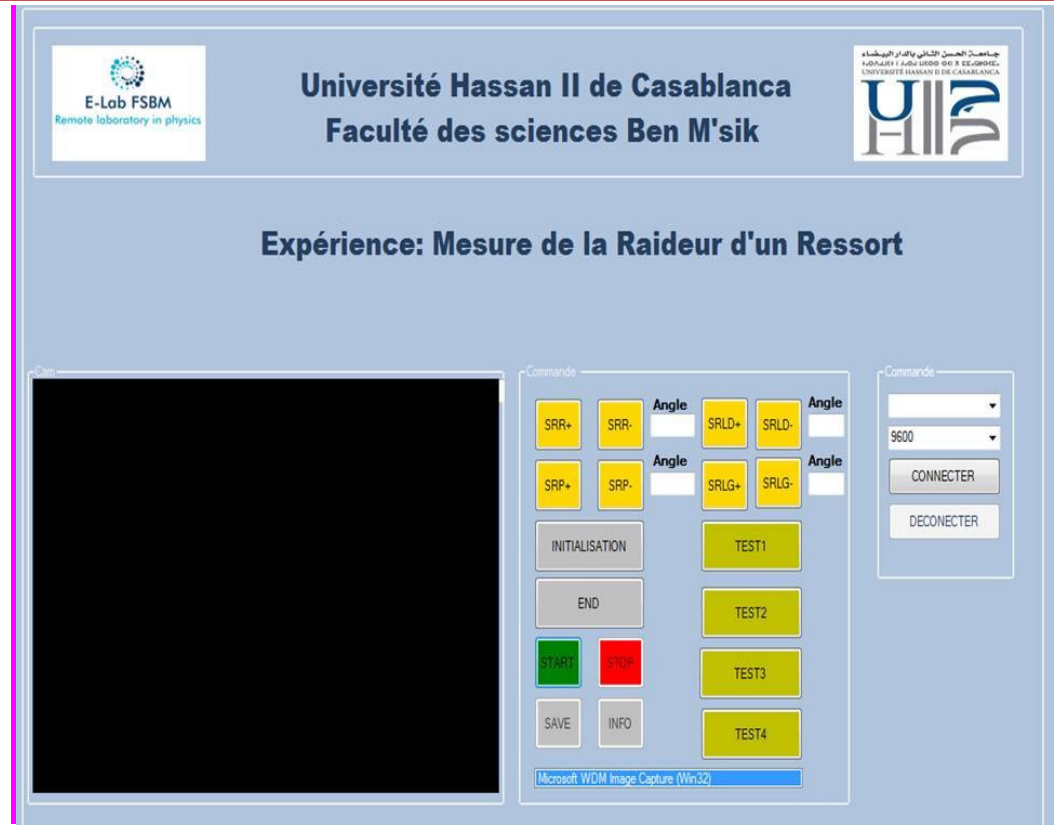

Figure 5 Application Interface

\section{Discussion}

The paramount importance of the establishment of remote laboratories is to prepare an easy environment, flexible as possible for all students. The e-lab user interface has been designed with the intent to be easily usable for all categories of students, who are accustomed to video games, chats and video conferences. The technique represented in this article aims to reduce the financial and human resource costs for all establishments concerned. As well as any problems of the dangerous kind of experiences and the difficult manipulations will disparate. The Fig. 6 illustrates remote laboratory on a real time.

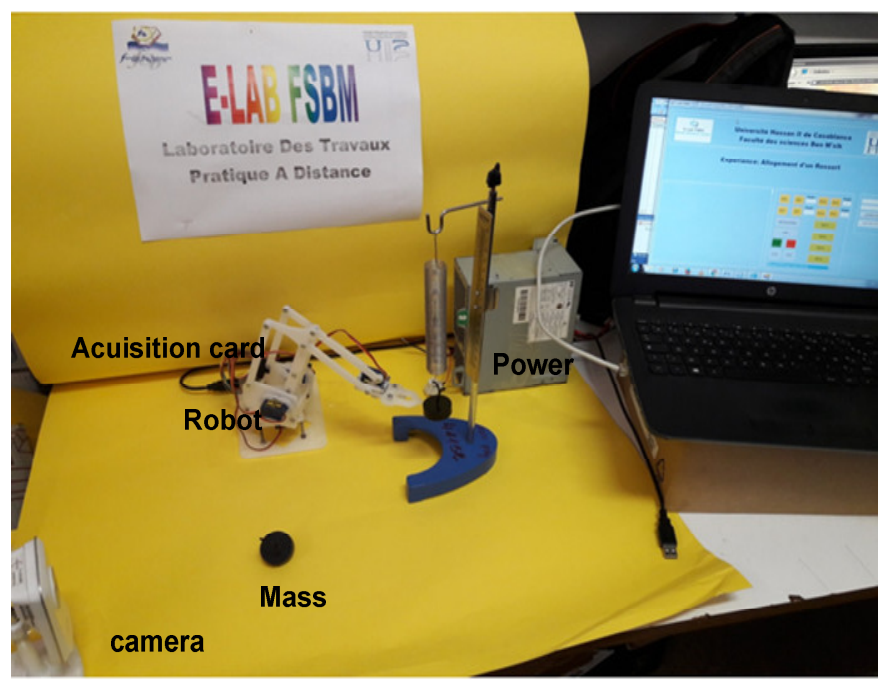

Figure 6 Remote Laboratory in Real Time 


\section{Conclusion}

The forms of Internet learning have been expanded including live physical experiments that much more complicated to implement compared to lecture modules. In this project, we first compared remote laboratories and practical laboratories. The result is a remote laboratory platform based on a web technology, the remote laboratory environment represented in this paper is e-lab platform Constituted by those equipments locally controlled by a computer (robotic arms). As a platform e-lab is evolving into a Reusable service web application, it can control other laboratory equipments then unite them on a unique virtual workbench. For more we are looking in future to create a chatting space because when students become confused, they often attempt to alleviate the confusion by communicating with comrade, or with the professor then the platform will solve this problem, Also give the possibility to tutors to supervise the students work online, as well as they can indicate them on a real time.

\section{REFERENCES}

[1] J. V. Nickerson, J. E. Corter, S. K. Esche, and C. Chassapis, "A model for evaluating the effectiveness of remote engineering laboratories and simulations in education," Comput. Educ., vol. 49, no. 3, pp. 708725, Nov. 2007.

[2] A. Alexiou, C. Bouras, and E. Giannaka, "Virtual laboratories in education," in Technology Enhanced Learning, Springer, 2005, pp. 19-28.

[3] O. Dziabenko and J. García-Zubía, IT Innovative practices in secondary schools: Remote experiments, vol. 10. Universidad de Deusto, 2013.

[4] A. A. TALEB, A. FAHLI, and M. MOUSSETAD, "Mise en Oeuvre d'une Télé-Séance de TP de Physique Nucléaire" Rétrodiffusion de Particules $\alpha . "$

[5] D. MECHTA, "Plate-forme pour les travaux pratiques à distance sur le Web," Ferhat Abbas, Algrie, 2012.

[6] M. A. Bochicchio and A. Longo, "Hands-On Remote Labs: Collaborative Web Laboratories as a Case Study for IT Engineering Classes,” IEEE Trans. Learn. Technol., vol. 2, no. 4, pp. 320-330, Oct. 2009.

[7] U. Hernandez-Jayo and J. Garcia-Zubia, "Remote measurement and instrumentation laboratory for training in real analog electronic experiments," Measurement, vol. 82, pp. 123-134, Mar. 2016.

[8] M. R. Laskar, R. Bhattacharjee, M. S. Giri, and P. Bhattacharya, "Weather Forecasting Using Arduino Based Cube-Sat," Procedia Comput. Sci., vol. 89, pp. 320-323, 2016.

[9] M. Teng, H. Considine, Z. Nedic, and A. Nafalski, "Current and Future Developments in Remote Laboratory NetLab," Int. J. Online Eng. IJOE, vol. 12, no. 8, p. 4, Aug. 2016.

[10] C. Depover, F. Orivel, and Institut international de planification de l'éducation, Les pays en développement à l'ère de l'e-learning. Paris: Unesco, Institut international de planification de l'éducation, 2012. 